DOI 10.37882/2223-2982.2022.01.23

\title{
ОСОБЕННОСТИ ВЗАИМОДЕЙСТВИЯ ПЕДАГОГОВ И УЧАЩИХСЯ В ПРОЦЕССЕ ПЕРСОНИФИЦИРОВАННОГО ОБУЧЕНИЯ В ШКОЛАХ ФИНЛЯНДИИ
}

\section{PECULIARITIES OF INTERACTION BETWEEN TEACHERS AND PUPILS IN THE PROCESS OF PERSONALIZED LEARNING IN FINNISH SCHOOLS}

Y. Polyakova

Summary: This article discusses the process of interaction between teachers and pupils in personalized learning of Finnish schools. The factors of successful personalized approach to students are identified, as well as the features of communication between teachers and students in the context of distance personalized learning in Finland.

Keywords: personalized learning, personalized approach, pedagogical interaction, Finnish schools.

\author{
Полякова Яна Юрьевна \\ Аспирант, Московский педагогический \\ государственный университет \\ yan3613@yandex.ru
}

Аннотация: В данной статье рассматривается процесс взаимодействия учителей и обучающихся в рамках персонифицированного обучения в Финских школах. Выявляются факторы успешного персонализированного подхода к ученикам, а также особенности коммуникации педагога и учащихся в условиях дистанционного персонифицированного обучения в Финляндии.

Ключевые слова: персонифицированное обучение, персонифицированный подход, педагогическое взаимодействие, школы Финляндии.
$\mathrm{B}$ заимодействие учителя с обучающимися- один из важных механизмов формирования межличностных отношений в школьной среде. Понимание процессов, лежащих в основе зарождения качественных отношений между учителем и учеником, всегда было ключевой задачей в области педагогики и психологии.

«...считается, что позитивные формы взаимодействия между учителем и учеником стимулируют обучение ребенка в школе и поддерживают учащегося, столкнувшегося со школьными требованиями и правилами школьной жизни, особенно на начальном этапе обучения» [8].

Эффективный процесс взаимодействия между учителем и учеником способствуют формированию у ребенка чувства уверенности в своих силах, а также позитивного отношения к процессу обучения. Именно поэтому процесс взаимодействия и выстраивания отношений педагога и обучающихся является актуальной темой не только в Финляндии, но и в России.

«Под педагогическим взаимодействием в педагогической психологии чаще всего понимают систему отношений между педагогом и учащимися, проявляющуюся в совместной деятельности, в ходе которой осуществляется образование и воспитание» [4].

Взаимодействие учителя и ученика в процессе персонифицированного обучения играет решающую роль в его последующем развитии и реализации себя как личности. Исходя из этого факта, данное взаимодействие становится основным средством обмена своими знаниями, идеями, чувствами, мнениями между учителем и учениками. Для продуктивного взаимодействия с учениками в процессе персонифицированного обучения, учителя используют специальные стратегии и подходы.

Следует согласиться с мнением Л.С. Подымовой, Т.А. Головятенко о том, что «основными направлениями деятельности по организации персонифицированного подхода к субъектам инновационной педагогической деятельности являются: психолого-педагогическая диагностика образовательных потребностей учителей, воспитателей, социальных педагогов и других участников образовательных отношений, обеспечение развивающего характера образовательной среды, социально-педагогический мониторинг личностно-профессионального развития, педагогическая экспертиза условий и образовательных программ повышения квалификации, обеспечивающих выбор индивидуальных траекторий развития, социально-педагогическое проектирование вариативных образовательных сред» [7, с.29].

В 2015 году исследователь по имени Джон Хэтти выявил ряд факторов, влияющих на эффективное персонифицированное обучение детей. Создание позитивной и благоприятной атмосферы в классе в сочетании с продуктивными отношениями между учителями и их учениками обеспечивает платформу, на которой происходит 
эффективный процесс обучения [3].

Эмили Галлахер опубликовала статью, в которой содержится информация о дальнейших исследованиях влияния отношений между учителем и учеником на социальные и академические результаты. В этой статье она подчеркивает, что учащиеся, поддерживающие позитивные отношения со своими учителями, с большей готовностью решают академические задачи и работают над своим социально-эмоциональным развитием [2].

Политика в области образования, направленная на повышение успеваемости учащихся в Финляндии, сделала сильный акцент на поощрении школ к созданию оптимальной среды обучения и установку образовательных траекторий, которые лучше всего помогут ученикам достичь своих целей.

Сегодня педагог в Финляндии имеет возможность выбора программы, учебно-методического комплекса, форм и методов обучения.

В процессе модернизации образования требования к качеству обучения и развитию полезных умений школьников постоянно возрастает. Сегодня школа несет ответственность не только за усвоение учащимися материала, но и за развитие личности ребенка. Поэтому учителя финских школ делают акцент на формировании правильной мотивации обучающихся, помощь в постановке целей, а также на создание атмосферы доверия.

«Личностно-ориентированный подход в современном образовательном процессе в Финляндии предопределяет двойное положение педагога - быть одновременно учителем школьного предмета и психологом. С того момента, как педагог сможет выстроить учебный процесс с учетом психологических особенностей детей, раскрыть познавательные возможности каждого ученика и в соответствии с этим составить для него индивидуальную образовательную траекторию саморазвития, эффективность учебной деятельности повышается, учебный процесс становится более увлекательным, комфортным и, в итоге, способствует повышению качества обучения и удовлетворенности учителя своим трудом» [3, с.10].

В связи с этим, личная готовность учителя к взаимодействию с обучающимися, которая реализуется в его профессионализме и выражается в творческом подходе, поиске наиболее эффективных способов решения возникающих проблем, в способности быстро принимать решения в критических ситуациях, играет важную роль в процессе формирования системы взаимодействия между ними.

«Личностно-ориентированная модель взаимодей- ствия учителя и учащихся характерна для финской педагогики, построенной на принципах признания права каждой стороны быть субъектом образовательного процесса. Противоречия между преподавателем и учеником разрешаются путем сотрудничества, где каждая сторона взаимодействия имеет определенную свободу в выборе содержания, форм деятельности, согласовывая свои претензии и права. В такой модели организации образовательного процесса отношения между ними строятся на реальной основе взаимного признания и взаимопонимания, а демократический стиль руководства становится преобладающим» [8].

Финские учителя стараются подобрать наиболее эффективные средства взаимодействия с учащимися в персонализированной учебной среде, где построение отношений и доверие формируют основу всего, что происходит в классе.

Чтобы по-настоящему персонифицировать процесс обучения, учителя Финляндии должны иметь поддержку и свободу, которые им необходимы, чтобы понимать и поддерживать каждого ребенка комплексно. Финские учителя должны обладать особыми умениями, чтобы помочь и направить каждого ученика подходящими способами в различных ситуациях: уникальная семейная ситуация, академические сложности, проблемы социализации и так далее.

Идея о том, что финские ученики принимают участие в построении своей собственной траектории обучения, то, как они демонстрируют полученные знания, работают над индивидуальными заданиями или работают в группах в течение дня, изначально может показаться несистематизированным процессом. Однако, ученик, который чувствует, что ему доверяют, который несет ответственность за свое обучение и осознает свою роль в развитии учебной среды, является более целеустремленным и успешным.

Одной из основных сильных сторон финской системы образования является ее способность гарантировать одинаковые образовательные возможности для всех, независимо от социального или экономического положения. Вместо конкуренции и сравнения школа фокусируется на поддержке и руководстве для учеников как личностей.

У юных учеников один и тот же учитель по всем или большинству предметов, который поддерживает их эмоционально и дает чувство защищенности. Взаимоотношения учителя и ученика - партнерские, что подразумевает взаимное уважение.

Педагог также следит за тем, чтобы в классной атмосфере не было дискриминации и притеснений. Оце- 
нивание успеваемости обычно начинается только после того, как учащиеся переходят в пятый класс. Отношения между учениками и учителями дружеские и непринужденные, а мотивация основана на поощрении, а не на наказании.

Доверие в отношениях учителя и обучающихся играет особенно важную роль.

При необходимости ученику оказывается помощь, которая включает в себя: корректирующее обучение в небольших группах, индивидуальные консультации и обучение учеников в соответствии с индивидуальными условиями, даже когда они учатся в одном классе с другими.

В основе развития системы взаимодействия учителя и ученика в современных финских школах заложены принципы когнитивной и гуманистической психологии, чем обусловлена активная позиция ученика в процессе обучения.

Также важно подчеркнуть, что даже во время дистанционных занятий финские педагоги придерживаются персонифицированного подхода к обучению и взаимодействию с детьми.

«Когда в Финляндии речь заходит об онлайн-обучении и дистанционном обучении, то, первым делом, это касается платформ - и тех, на которых проходит обучение, и тех, которые используются в качестве дополнительных. У таких платформ есть особенность - они помогают финским педагогам отслеживать индивидуальный прогресс каждого ученика. В процессе персонифицированного онлайн-обучения это крайне важно. Та информация, которую собирают такие платформы, является аналитикой обучения, и очень необходима и полезна в особенности при групповом обучении. Учитель может определить, на ком из обучающихся нужно больше заострить внимание, или дать больше заданий для помощи и поддержки» [6].

Наряду с составлением учебной программы учителя Финляндии играют ключевую роль в оценке учащихся. Финские школы не используют стандартизированные тесты для определения успеваемости учащихся.

Хотя практика оценивания хорошо обоснована, национальная учебная программа и образовательная политика Финляндии уделяют первоочередное внимание индивидуальному обучению и творчеству как важной части работы школ, поэтому об успеваемости каждого ученика в школе судят больше по его индивидуальному прогрессу и способностям, чем по статистическим пока- зателям.

Суть оценивания в финских школах заключается в построении обратной связи и поощрении, которые помогают ученику продвигаться вперед и распознавать свои сильные стороны и возможности для развития.

Также для финнов чрезвычайно важно, чтобы радость, получаемая от процесса обучения, не была утрачена. По этой причине во многих финских школах происходит отказ от оценивания учащихся в баллах на начальном этапе образования. Важно чтобы у ребенка не появилось мнение, что он не соответствует стандарту по определенным изучаемым предметам.

Индивидуальный подход к оцениванию образовательных результатов обучающихся в финских школах обеспечивается через непрерывное оценивание, чтобы направлять учеников и помогать им в процессе обучения ликвидировать пробелы в усвоении учебного материала, преодолеть трудности в обучении. Каждый учащийся получает отчет не реже одного раза в учебный год.

Одна из задач финского персонифицированного подхода к обучению - развить у учеников способности к самооценке. Цель этого -поддержать рост самопознания и учебных навыков, а также помочь ученикам быть в курсе своего личностного и академического прогресса.

Оценки в школах Финляндии в основном используются для выявления областей, в которых у обучающихся возникают трудности, а не для дифференциации успеваемости учащихся. Учащиеся получают индивидуальную обратную связь, которая помогает им восполнить пробелы в понимании определённых тем.

Оценивание результатов обучения проводится постоянно, этот процесс поощряет и направляет учеников. Реализуя индивидуальный подход к оцениванию, финские учителя имеют возможность дополнительной мотивации ребенка к достижению высоких результатов.

Таким образом, оценивание является инструментом поддержки для учителей, позволяющей им на раннем этапе корректировать индивидуальные образовательные маршруты обучающихся.

В заключении можно сделать вывод, что развитие устойчивых педагогических взаимоотношений между учителем и учеником является фундаментальным аспектом персонифицированного подхода в процессе обучения и воспитания в школах Финляндии, а педагогическое взаимодействие осуществляется с учетом особенностей финского подхода к образованию в целом. 


\section{ЛИТЕРАТУРА}

1. Emily K. Gallagher. Teacher Caring as a Protective Factor: The Effects of Behavioral/Emotional Risk and Teacher Caring on Office Disciplinary Referrals in Middle School. URL:https://www.researchgate.net/scientific-contributions/Emily-K-Gallagher-2111977515 (дата обращения: 29.10.20).

2. Hattie and his high impact strategies for teachers. URL:https://www.evidencebasedteaching.org.au/hattie-his-high-impact-strategies/ (дата обращения: 13.11.20).

3. Yakovlev B.P. Psychologically-pedagogical conditions of forming the personality preparation to the creative interaction of teacher and students at modern educational process / B.P. Yakovlev, V.D. Povzun // European Journal of Natural History. - 2010. - No 5. - P. 41-44.

4. Дюкова Л.А. Сущность категории «взаимодействие» в современной педагогике//Специфика педагогического образования в регионах России. 2009.

5. Дьюи, Джон // Педагогический энциклопедический словарь / Под ред. Б. М. Бим-Бада. — М., 2003. — С. 356.

6. К Кючевое при обучении онлайн: грамотное планирование, открытость, прозрачность и терпение. URL:http://edu-marathon.org/digital-learning-2020 (дата обращения: 02.11.20).

7. Подымова Л.С., Головятенко Т.А. Проблема организации персонифицированного образовательного пространства//Высшее образование сегодня. 2020. - № 1.- - .28-30.

8. Принципы финского образования: умная Финляндия. URL:https://terve.su/printsipy-finskogo-obrazovaniya/ (дата обращения: 17.10.20).

9. Современная зарубежная психология. Том 8. № 1. URL:https://psyjournals.ru/jmfp/2019/n1/ (дата обращения: 17.10.20).

○ Полякова Яна Юрьевна (yan3613@yandex.ru).

Журнал «Современная наука: актуальные проблемы теории и практики»

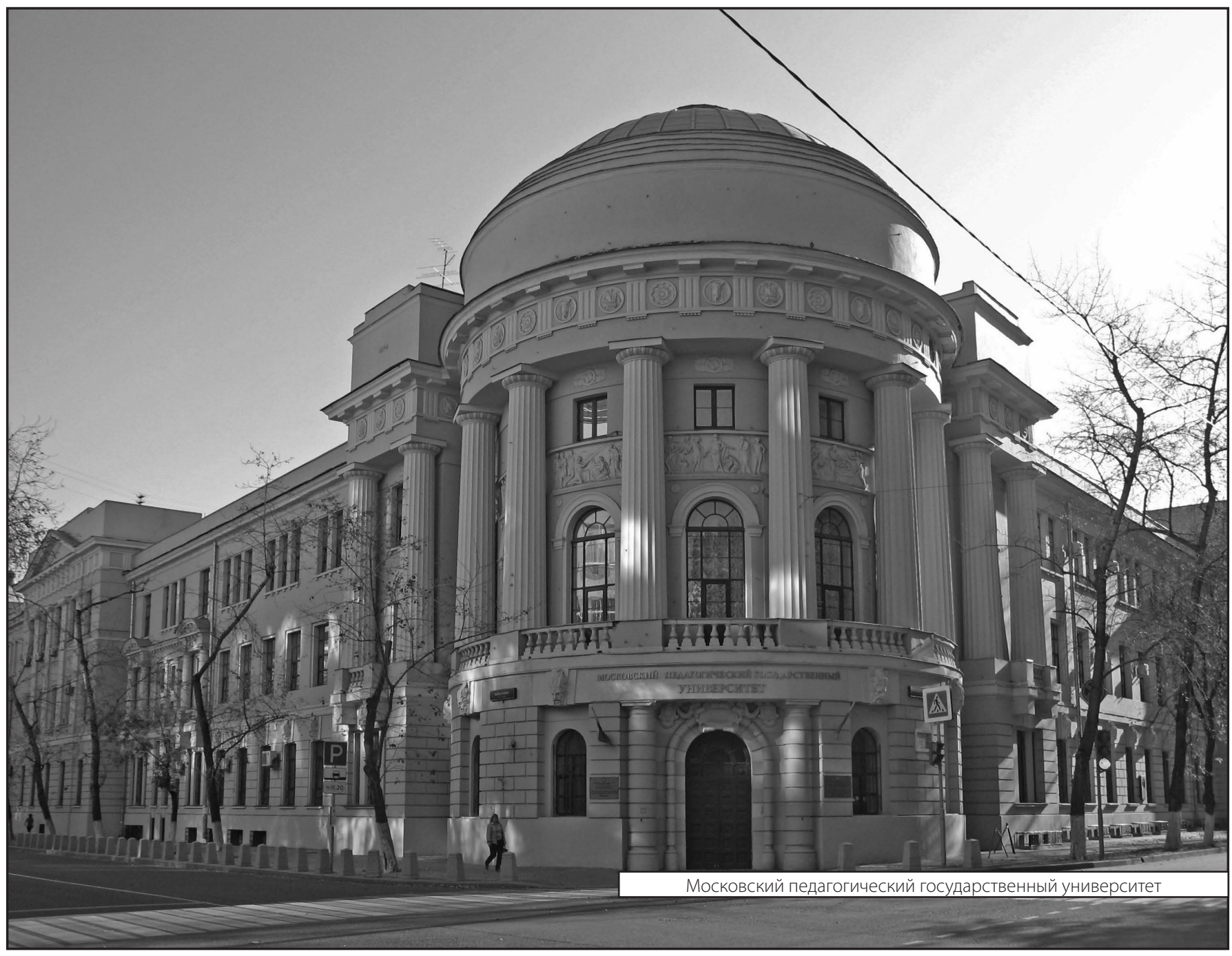

